\title{
The Impact of Covid-19 on Movie Industry in China During 2020
}

\author{
HeQing Wang ${ }^{1, *}$
}

\author{
${ }^{1}$ Beijing No. 2 Middle School, $11^{\text {th }}$ Grade \\ * Corresponding author. Email: 3356093158@qq.com
}

\begin{abstract}
Covid-19 has had a huge impact on the world economy as a whole, including China, and the impact on the film industry is inevitable. This article studies the impact of Covid-19 on cinema ticket sales and industry development. Using data and graphic analysis, it shows the changes in movie theater ticket sales, screen numbers, national film production, and so on before and after the epidemic. It finds that Covid-19 had a serious negative impact on the box office and the film industry, and the recovery was pretty slow.
\end{abstract}

Keywords: Movie Box Office, Covid Pandemic, Revenue, Industry Development, China Economy

\section{INTRODUCTION}

This essay studies the impact of Covid-19 on cinema ticket sales and industry development. Covid-19 impacts direct contact businesses such as hospitality, traveling, cinema, and so on, which caused huge economic losses to all kinds of enterprises. 460,000 companies closed in the first quarter of 2020 ([1] Tianyancha, 2020) and China's annual GDP growth has slowed from $6.1 \%$ to $2 \%$ ([2] China Academy of Social Sciences, 2020). The economy has suffered for a while.

Particularly, I am interested in the film business and its suffering. As mentioned earlier, movie theater needs a direct contract. When people watch movies together, they sit very close to each other. However, Droplet transmission happens to be one of the main transmission routes of Covid-19. This shows that sitting together and watching a movie in a closed room with cycled airflow can easily cause the spread of the virus. What's more, this has happened right before the biggest festival in China, Chinese New Year, which is the New Year movie season and box office booms time. Box office sales during this period account for about 10 percent of annual sales ([3] Zhi yan Consulting group, 2020).

As the Chinese government attaches great importance to the prevention and control of the epidemic and has introduced various policies and measures promptly, by May 2020, the epidemic in China had significantly improved. Since then, this trend of improvement has been maintained, and the vast majority of new Covid-19 cases have been the imported cases from abroad rather than domestic spreads.

In the situation where the epidemic situation is improving, since July 2020, cinemas in China have also been gradually opened, projected to become the world's biggest in 2020. However, it will remain in the shadow of the United States for a few more years, according to a recent report ([4] Marrian Zhou, Nikkei, 2020). The COVID-19 pandemic will severely affect China's overall growth trajectory, and total cinema revenues will shrink $4.8 \%$ on average each year through 2024 , according to a report released this month by PwC. The consultancy forecasts that the U.S. will remain the largest cinema market for at least the next five years, with total revenue reaching $\$ 10$ billion in 2024 , compared to $\$ 8.1$ billion for China. The reason is that China's cooling economy, the pandemic, and tightening censorship have all combined to squeeze the country's film industry.

This study mainly focuses on two parts: the impact of Covid-19 on movie box office and revenue, and the effect of the pandemic on movie industry development. This aims to identify the overall impact on the movie industry under extreme market shock.

\section{THE IMPACT OF COVID-19 ON MOVIE REVENUE}

Box Office refers to the revenue of a theater or the revenue of a movie released in a theater. In the film industry, the box office has become one of the important indicators to measure the success of a film. It can be 
calculated by the number of audiences or ticket income, which is generally directly used to measure the popularity of a film.

In 2020, twelve of the fifteen film and television media companies issued performance forecasts suffered losses, while 3 made profits. There is a total loss of 15 billion yuan, among which Wanda Film alone lost more than 6 billion yuan. ([5] South Money, 2021)

This study mainly covers analysis on three aspects that related to China's box office, which are onsite theater box office during China Spring Festival, box office change in China, and single month box office nationwide in 2020 .

\subsection{Onsite theater box office during China Spring Festival}

As can be seen from the first picture below, the average yearly growth rate from 2015 to 2019 is $37.76 \%$ before the Covid 19 impact. Looking at the trend line, we can see that without Covid-19 impact, we will have at least 5.5 billion CNY box office in 2020 during the Lunar new year (generally January or February), a conservative estimation. If we hold more objective estimations based on the average growth rate, then we will see 8.13 billion CNY. However, the reality is that all the films scheduled to be released during the 2020 Spring Festival have been pulled out, causing the box office to drop to zero and cinemas to receive nothing.

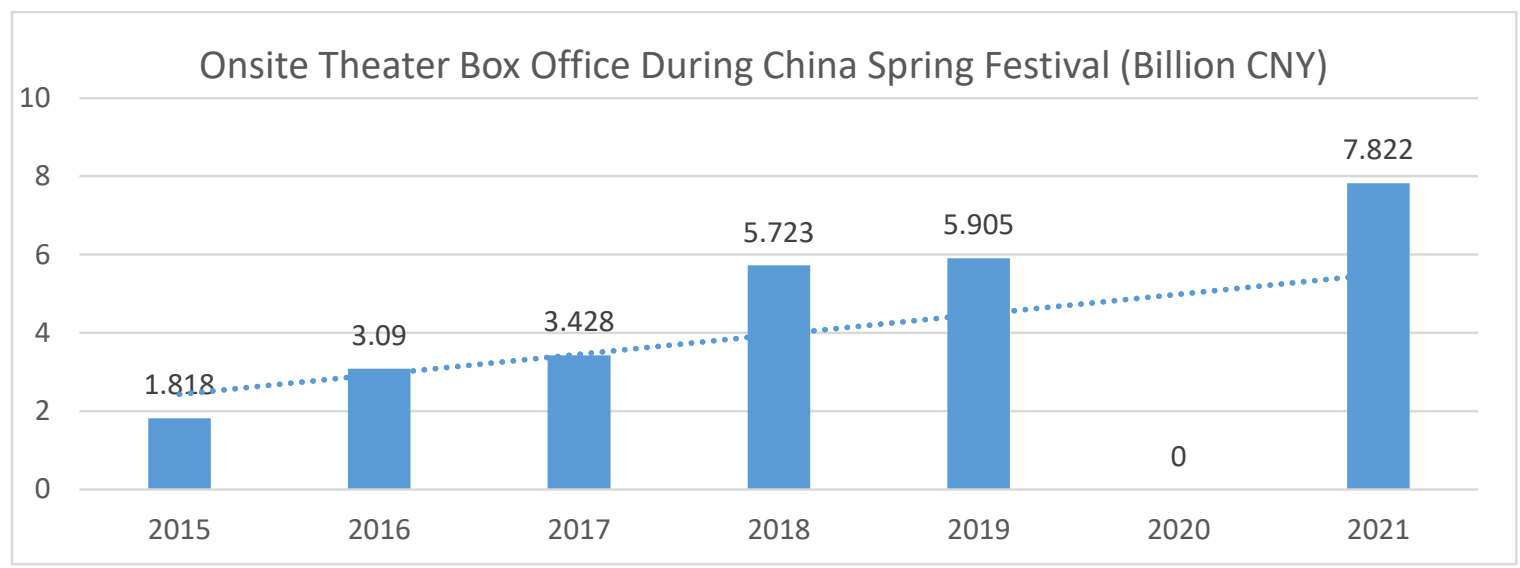

Figure 1: Onsite theater box office during China Spring Festival, 20th, February 2021

Data Source [6]: https://baijiahao.baidu.com/s?id=1692207727529869991\&wfr $=$ spider\&for $=p c$

\subsection{Box Office change in China}

The second picture below illustrates the average yearly growth rate from 2012 to 2019 is $43.23 \%$ before the Covid 19 impact. Looking at the trend line, we can see that without Covid-19 impact, we will at least 55 billion CNY box office in 2020, at conservative estimation. But, because of the Covid-19, a lot of people chose to watch the movie at home instead of the cinema. In addition, all the movies that were shown during the Spring Festival were pulled from theaters. Therefore, the box office was down sharply in 2020 .

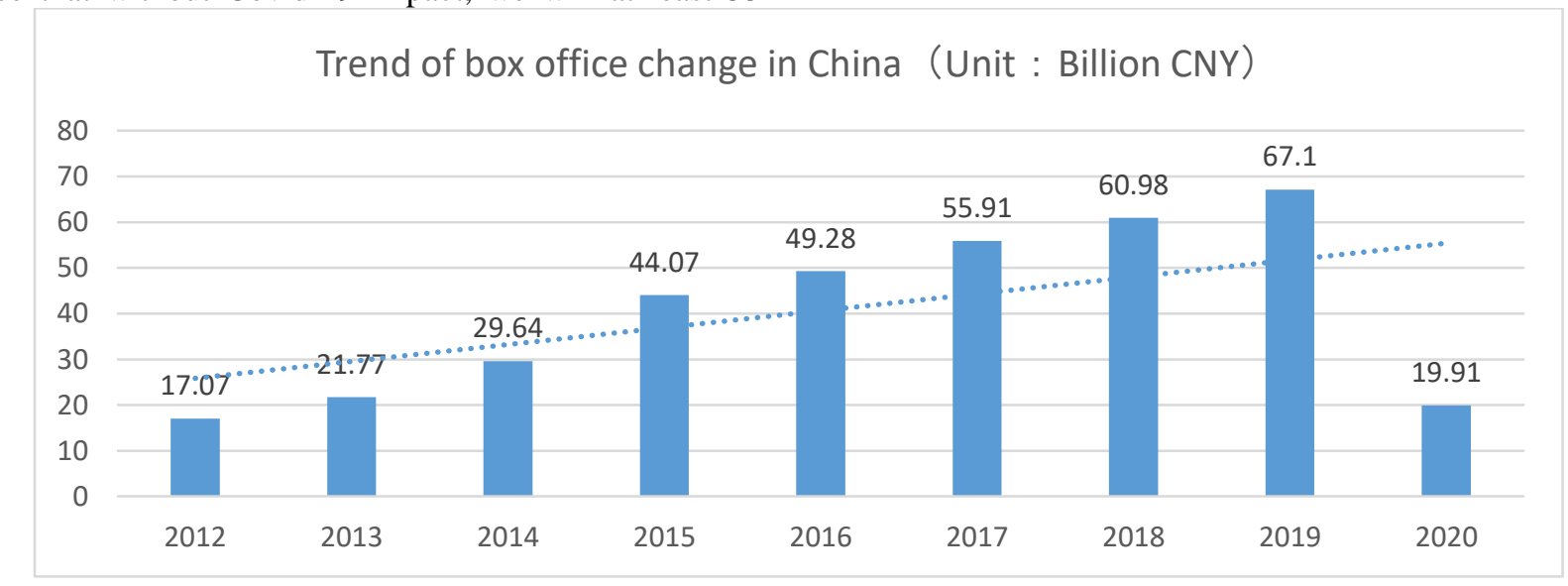

Figure 2: Box Office change in China, 13 ${ }^{\text {th }}$, March 2020

Data Source [7]: https://baijiahao.baidu.com/s? id $=1661053699471578983 \& w f r=s p i d e r \& f o r=p c$ 


\subsection{Single month box office nationwide in 2020}

The third graph below shows that from the end of January to the middle of July in 2020, because of the epidemic, all cinemas in China were closed, and the box office dropped to 0 . By the end of July, the situation was much better, but because of the fear of crowds and seatspacing, ticket sales grew only marginally. Until October, there was a significant increase in ticket sales, which were about twice as high as in August. Unfortunately, in November and December, a second wave of the epidemic hit, causing the demand for people to go to the cinema to see the film to decline again.

Covid-19 has had a huge negative impact on the film box office and the film industry as a whole, especially because of the zero box office revenue during the Spring Festival.

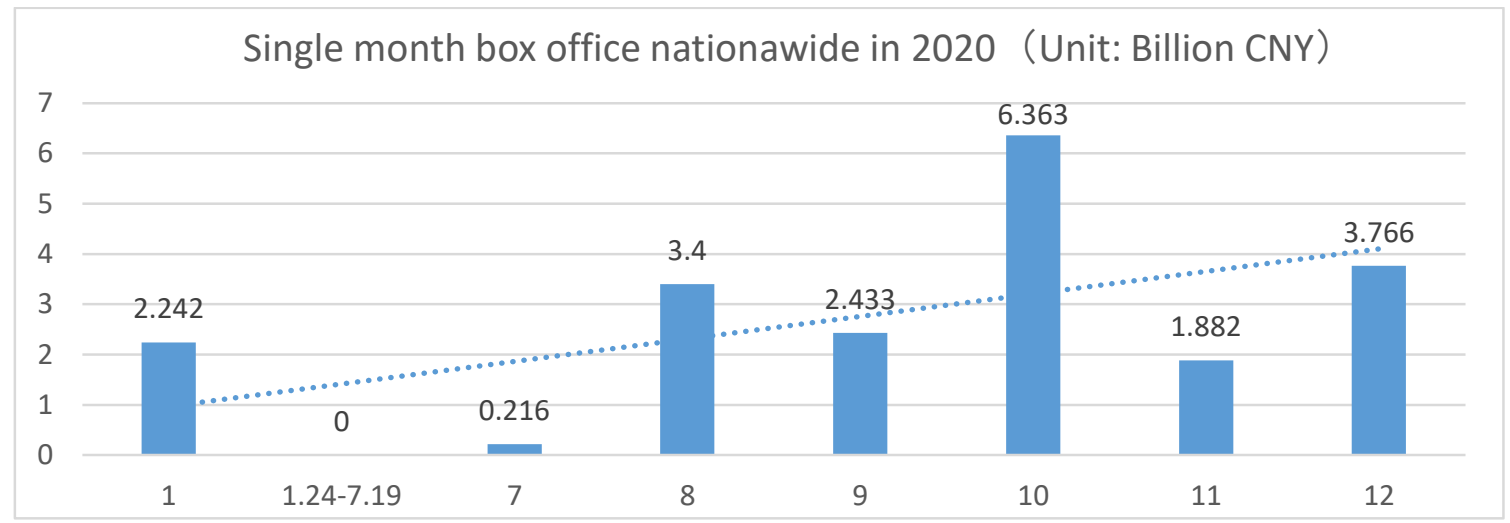

Figure 3: Single month box office nationwide in 2020, 18th, January 2021

Data Source [8]: http://finance.sina.com.cn/tech/2021-01-18/doc-ikftssan7572855.shtml

\section{THE EFFECT OF THE PANDEMIC ON MOVIE INDUSTRY DEVELOPMENT}

From the perspective of industrial attributes, different from other industries in the field of material production, the film industry not only has economic attributes but also has social and cultural attributes.

From the perspective of economics, the film product itself has an exchange value and can meet the market demand, so it has economic properties. The film production process is very special, it is a concept first creation, from the abstract discussion to the actual implementation of a series of processes. Therefore, this process involves the participation of many different types of enterprises and various forms of economic activities. At the same time, because films can be mechanically reproduced in large quantities, the marginal cost is low. Therefore, for the film industry, the "content" production of film products is one of the most important factors in its product competitiveness.

A film is an art form with profound social and cultural implications. The film itself can carry information, and its essence is to tell a story through flowing images. The narration has also become the root of the ideology of the film. In the process of narration, it contains the transmission of culture.

To realize the leapfrog development of "from big to strong", China's film industry should seize the new opportunities in the new era and take a step ahead, so as to achieve the goal of becoming a powerful country in the film industry.
From black and white to color, from plane to threedimensional, from film to digital, the development and progress of the film industry have always been through the integration and innovation of technology and art. Hollywood film "Avatar" developed world-leading 3D virtual image photography, facial performance capture, and other technologies to shock the world with lifelike visual effect; The Wandering Earth, with its high level of special effects and a story with Chinese connotations, has been a box-office success both at home and abroad. Naked eye 3D/4D technology, VR technology, mixed reality MR technology, holographic technology, panoramic sound technology, etc., provide new opportunities for breakthroughs in film technology.

In the field of film publicity and promotion, distribution enterprises should timely study the changes of audience's movie-watching psychology and stratification, and conduct film publicity and promotion in a diversified way. At the same time, film publicity and distribution should go out, seize the promotion opportunity, and tell Chinese stories well.

I have done detailed research and analysis on three aspects that related to the whole film business, which is the number of screens in China from 2012 to 2020, the Number of Registrations and Logout of Cinema Related Enterprises from January to June in 2020, and the changing trend of the national film production from 2012 to 2020 . 


\subsection{Number of screens in China from 2012 to 2020}

The first picture below illustrates that from 2012 to 2020, the number of movie screens in China has been on the rise. In eight years, the number of screens has grown nearly sixfold. The average yearly growth rate from 2012 to 2020 is $24.84 \%$. The fastest increase was in 2015 , at $34.06 \%$. In 2020, because of the sudden epidemic, fewer people choose to go to the cinema. But the number of screens has increased in line with the trend, although it is certainly much slower than the rate of growth in previous years. Thus, many theaters lost a lot of money during the epidemic.

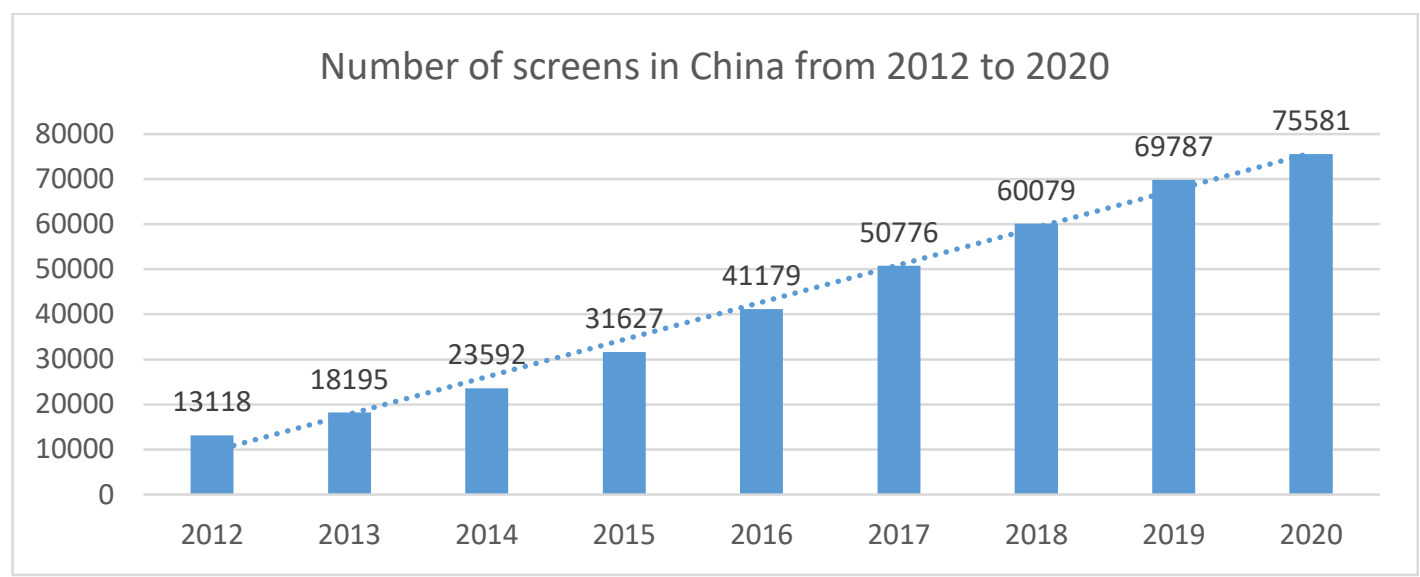

Figure 4: Number of screens in China from 2012 to 2020, 20 ${ }^{\text {th }}$, July 2020

Data Source [9]: https://www.zhihu.com/question/378785248/answer/1171211941

After the epidemic gradually improved, people's demand for watching movies also recovered. However, the supply of the number of screens could not be recovered for a while, resulting in excess demand. A short-term imbalance between supply and demand has led to ticket prices rising. To be more specific, the number of screens dropped by $18.9 \%$ relative to the preepidemic growth rate, but the number of people going to the movies recovered in 2021, so the ticket prices roughly doubled. The situation before the epidemic and after the complete recovery is illustratively shown in Figure 5 below. It provides the situation of decreasing supply and non-changing demand, with the increasing price.

It is worth mentioning that the specific changing dynamic of people's movie-watching demand in 2020 is relatively complex as the demand is basically constrained for a while and gradually increased, which needs further research.

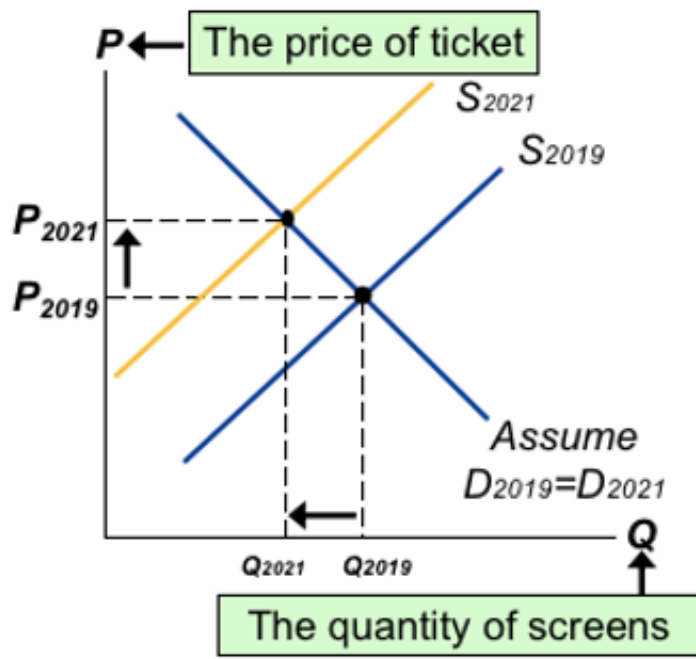

Figure 5: The Model of Demand and Supply for Movie Ticket Price: Before and After the Pandemic

\subsection{The number of registrations and logout of cinema-related enterprises from January to June in 2020}

As can be seen from the second picture below. In 2020 , the overall number of cinemas is still on the rise, despite the outbreak of the epidemic. The number of registrations always greater than the number of logouts. In February, because the epidemic was the most severe, the number of registrations dropped sharply, but it picked up again in March. In the following months, although there were fluctuations, the number remained above 100 . Besides, the number of logouts has also been on the rise, 
especially since February, the number of logouts has been around 20-30. I don't think there would have been so many write-offs businesses if it hadn't been for the epidemic.

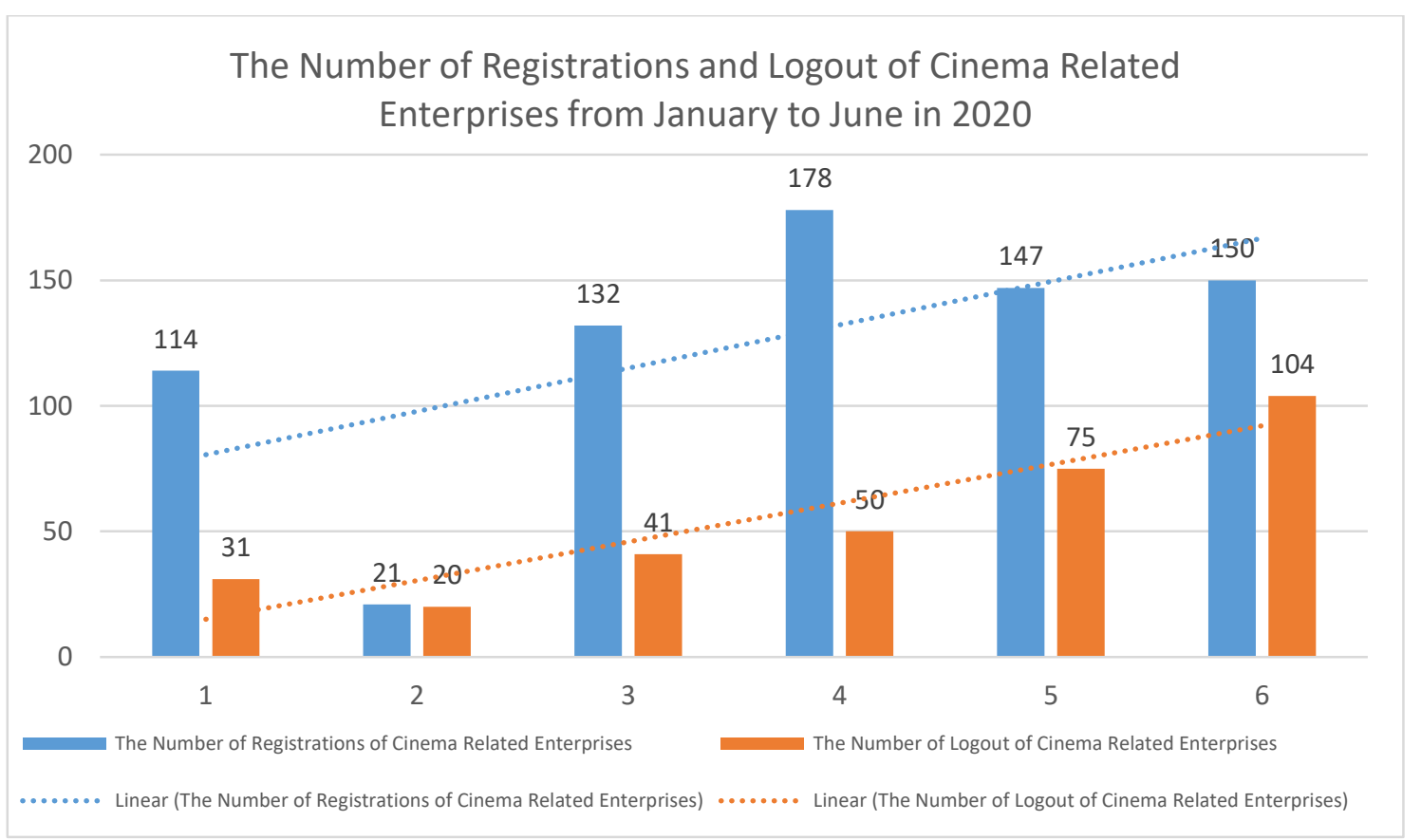

Figure 6: The number of registrations and logout of cinema-related enterprises from January to June in 2020

Data Source [10]: https://www.sohu.com/a/408760701_99957768

\subsection{The changing trend of the national film production from 2012 to 2020}

The third graph below shows that with the gradual improvement of people's living standard, our demand for going to the cinema to see movies increases. Also, the government is paying more attention to national films, and the quality of films has improved. Thus, the number of national film production is also increasing. The average yearly growth rate from 2012 to 2019 is $2.55 \%$ before the Covid 19 impact. Looking at the trend line, we can see that without Covid-19 impact, at least 920 new national films will be produced, at conservative estimation. If we hold more objective estimations based on the average growth rate, then we will see 1063.44 billion CNY. However, only 650 new films were produced in 2020, at least $30 \%$ down from the trendline.

Covid-19 has slowed the growth of movie screens and the production of national films. Besides, a lot of companies went bankrupt because of low attendance.

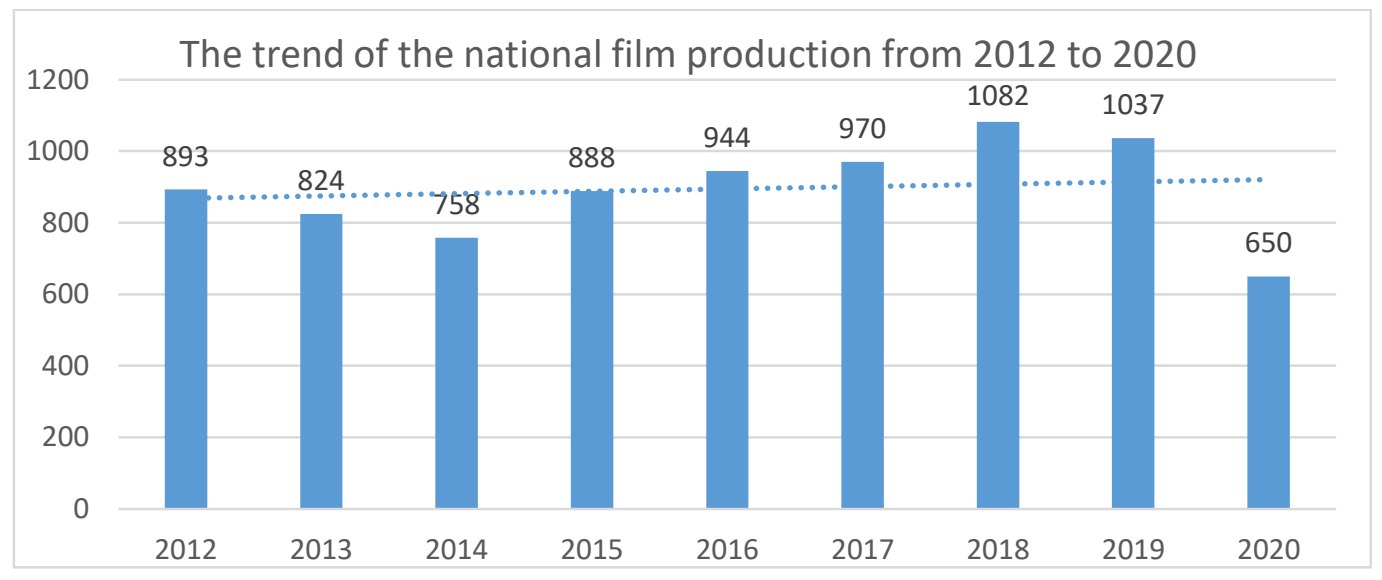

Figure 7: The changing trend of the national film production from 2012 to $2020,5^{\text {th }}$, January 2021

Data Source [11]: https://www.askci.com/news/chanye/20210105/1639481332253_2.shtml 


\section{CONCLUSION}

Covid-19 has had a huge negative impact on the film box office and film industries that a number of companies went bankrupt because of low attendance. It also has slowed the growth of movie screens and the production of national films which means that the epidemic has seriously hampered the development of films in China.

\section{REFERENCES}

[1] Web: https://www.tianyancha.com/, December 2020

[2] China Academy of Social Sciences, 2020, Economics Blue Paper: 2019 China Economic Trend Analysis and Forecast

[3] Zhi yan Consulting group, Panoramic Survey, and Development Prospect Forecast Report of Chinese Spring Festival Film Market from 2019 to 2025

[4] Marrian Zhou, Nikkei staff writer, $23^{\text {rd }}$, September 2020, China's movie industry won't surpass the U.S. in 2020 after all: report

[5] http://www.southmoney.com, $7^{\text {th }}$, February 2021, Summary of the film industry market in 2020: How much did the listed film and television companies lose?

[6]https://baijiahao.baidu.com/s?id=1692207727529869 991\&wfr=spider\&for=pc, 20th, Feb. 2021, Onsite theater box office during Spring Festival

[7]https://baijiahao.baidu.com/s?id=1661053699471578 $983 \&$ wfr=spider $\&$ for $=$ pc, $13^{\text {th }}$, March 2020 , How do you view the impact of the epidemic on the film industry?

[8]http://finance.sina.com.cn/tech/2021-01-18/docikftssan7572855.shtml, Jan. 18 ${ }^{\text {th }}$ 2021, Electronic Information Office: National Box Office Monthly Report for December 2020

[9]https://www.zhihu.com/question/378785248/answer/ 1171211941, 22 $2^{\text {nd }}$, April 2020, How is the current outbreak affecting the film industry? 2020

[10]https://www.sohu.com/a/408760701_99957768, $20^{\text {th }}$, July 2020, A review of the impact of the epidemic on cinemas in the first half of 2020

[11]https://www.askci.com/news/chanye/20210105/1639 481332253_2.shtml, Jan. 5 ${ }^{\text {th }} .2021$, A summary of the development status of China's film market in 2020 and a forecast of its prospects in 2021 